\title{
Design of Serious Games for Students with Intellectual Disability
}

\author{
Cecilia Sik Lanyi \\ University of Pannonia \\ H-8200 Veszprem, Egyetem u. 10 \\ lanyi@almos.uni-pannon.hu
}

\author{
David Joseph Brown \\ Nottingham Trent University \\ Clifton Campus, Clifton Lane, NG11 8NS \\ david.brown@ntu.ac.uk
}

\begin{abstract}
We have designed and developed around 10 serious games under the EU Leonardo Transfer of Innovation Project: Game On Extra Time (GOET) project http://goet-project.eul. The project supports people with learning disabilities and additional sensory impairments in getting and keeping a job by helping them to learn, via games-based learning; skills that will help them in their working day. These games help students to learn how to prepare themselves for their working life, dealing with every day situations at work, money management, travelling independently etc. In this paper we will address the main games' design questions and our solutions to these to suit the needs of our target audiences. It is necessary to design the user interfaces for maximum accessibility and usability. In this way we will minimise the additional cognitive load placed on the user while navigating within the software. In order to achieve these goals we have followed published design guidelines, and placed emphasis of using graphics, animations and auditory output to promote user engagement and provide alternatives to text.
\end{abstract}

Keywords: serious games, intellectual disability, design, human computer Interaction

\section{INTRODUCTION}

We have designed and developed around 10 serious games under the EU Leonardo Transfer of Innovation Project: Game On Extra Time (GOET) project http:/lgoet-project.eul. The project supports people with learning disabilities and additional sensory impairments in getting and keeping a job by helping them to learn, via gamesbased learning; skills that will help them in their working day. These games help students to learn how to prepare themselves for working their working life, dealing with every day situations at work, money management, travelling independently etc.

The outputs of the project are: accessible, interactive Serious Games (computer games based learning) with embedded learning objectives in Personal Development and Employment Preparation, available online in a project portal; via the project website, as CDs and for mobile technologies and offline in published learning packs. These games which will be tested in all partner countries include:

- 3D Work Tour: simulates the first days at a workplace in a games 'mod' created using the Half Life 2 engine
- Cheese factory: teaches the students using fractions and percentages based on the popular Tetris Game.

- Memobile: reminds the client of the important things to do in preparing to leave the house and throughout their working day using mobile phone technology programmed using Java

- My Appearance: teaches the students the everyday "morning" tasks from getting up until leaving home using a Flash game.

- Route Mate: helps the client to plan and independently carry out their route to work developed on the Android Operating System.

- VR supermarket: helps to teach students about money management skills within a store environment developed using Flash.

The usability tests are finished in the middle of January 2010 and the detailed pedagogical tests will run until June 2010 .

In this paper we will address the main games' design questions and our solutions to these to suit the needs of our target audiences. It is necessary to design the user interfaces for maximum accessibility and usability. In this way we will minimise the additional cognitive load placed on the user while navigating within the software. In order 
to achieve these goals we have followed published design guidelines, and placed emphasis of using graphics, animations and auditory output to promote user engagement and provide alternatives to text.

\section{SERIOUS GAMES AND HCI}

Computer games have the capacity to take learning to a whole new level. Playing computer games has become one of today's most popular media activities for people of all ages. Virtual Reality (VR) games are popular among children and young people all over the world. "The current global player populations of the three game titles (of dozens) that was studied over the past few years (Lineage I, Lineage II and Word of Warcraft) totals over 9.5 million - a population which rivals, e.g. most US metropolises" [1]. "The computer gaming industry has now surpassed the "Hollywood" film industry in total entertainment market share, and in the USA sales of computer games now outnumber the sale of books." [2] (Doug Lowenstein, President, Interactive Digital Software Association)

\subsection{Serious games}

If we search for the phrase "serious game " on the internet we get more than 97 million results in only 0.27 seconds. This shows that serious games are increasingly popular. There are several definitions of serious games [3], [4], [5], but all agree that serious games or persuasive games are computer and video games used as persuasion technology or educational technology. They can be similar to educational games, but are often intended for an audience outside of primary or secondary education. Serious games can be of any genre and many of them can be considered a kind of edutainment [6].

\subsection{Benefits of serious games}

There may be real benefits in using games for learning: "... research has shown that learning is much more effective when the student has fun" [7]. This is one of the main reason for using games to educate, as much more is learned when the student is enjoying the education. Another reason is that "...computer games provide a good environment for learning because they are able to give instant feedback to the player, which is highly beneficial for learning" [8], [9].

Moreover:

- It is an audiovisual medium.

- It can be interactive.

- The treatment or situation can be reproduced, the same condition can be repeated several times.

- It can be adjusted to individual needs.
- Serious games have an effect on more than one sense, and can be more effective.

- It can help creativity, it can be varied.

- One can include the motivating qualities of games.

- They can be designed to ensure the user experiences success.

- One can use motivating audio feed-back.

- It can be used both in individual and smallgroup therapy.

\subsection{Human Computer Interaction}

Human Computer Interaction (worldwide used acronym is $\mathrm{HCl}$ ) is the study of how humans interact with computers and programs (used to be called Man Machine Interface too).

$\mathrm{HCl}$ is a discipline concerned with the design, evaluation and implementation of interactive computing systems for human use and with the study of major phenomena surrounding them. From a computer science perspective, the focus is on interaction and specifically on interaction between human(s) and computer(s) [10].

$\mathrm{HCl}$ is also a growing academic discipline. More than a dozen research journals in $\mathrm{HCl}$ are compiling practical results and theoretical frameworks to guide designers. These success stories in $\mathrm{HCl}$ and user interface design are paralleled and emulated in university courses, but change often comes about slowly. The resistance comes from technology-centred researchers who value mathematical formalism more than psychological experimentation [11] (Shneiderman, 2003, pp. 71.).

A critical component in designing multimedia software and serious games is the production of educational programs. Obviously, it is not a simple task to assess the effectiveness of a multimedia teaching system. The question is more complicated if the users have special needs [10]. The literature is increasingly attentive to „Design for All” principles (Universal Design).

\subsection{Intellectual disability}

There is a wide variation of cognitive impairments that could be categorized as Memory, Perception, Problem-solving, and Conceptualizing disabilities. Memory disabilities include difficulty obtaining, recognizing, and retrieving information from shortterm storage, as well as long-term and remote memory.

It is necessary to design multimedia software or web pages or serious games in ways that minimize the skills and abilities required to navigate within them. The designers need to define terms that may 
not be known to the cognitive disabled people. Some guidelines are:

- Minimize the cognitive load while navigating in the software

- Use graphics for navigation whenever possible

- Avoid animated graphics and the use of overlay large file sizes.

- Use animations and dynamic display with care.

People with Intellectual Disabilities experience low levels of employment and face barriers to employment. The UK Valuing People Report (Department of Health, 2001) and the Learning for Living and Work Report (LSC, 2006) have emphasised the need to promote and develop appropriate training and employment opportunities for this target audience. The Game On Extra Time (GOET) project provides a response to these calls, by the development of engaging and accessible serious games to develop work based skills in this target audience.

\section{DESING OF SERIOUS GAMES}

In this section the main design requirements of the "3d Work Tour", Cheese factory", My Appearance", Route Mate" and VR supermarket" games are described.

\subsection{D Work Tour}

3d Work Tour: simulates the first days at a workplace in a games 'mod' created using the Half Life 2 engine.

After selecting the language (Fig. 1) there are two possibilities: subtitles and video tour with BSL for hearing impaired users (Fig 2).

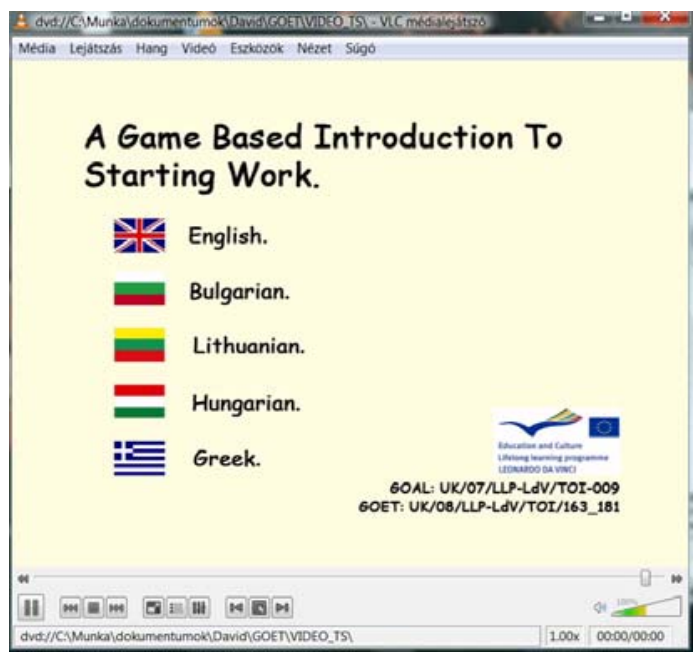

Figure 1: Language option.

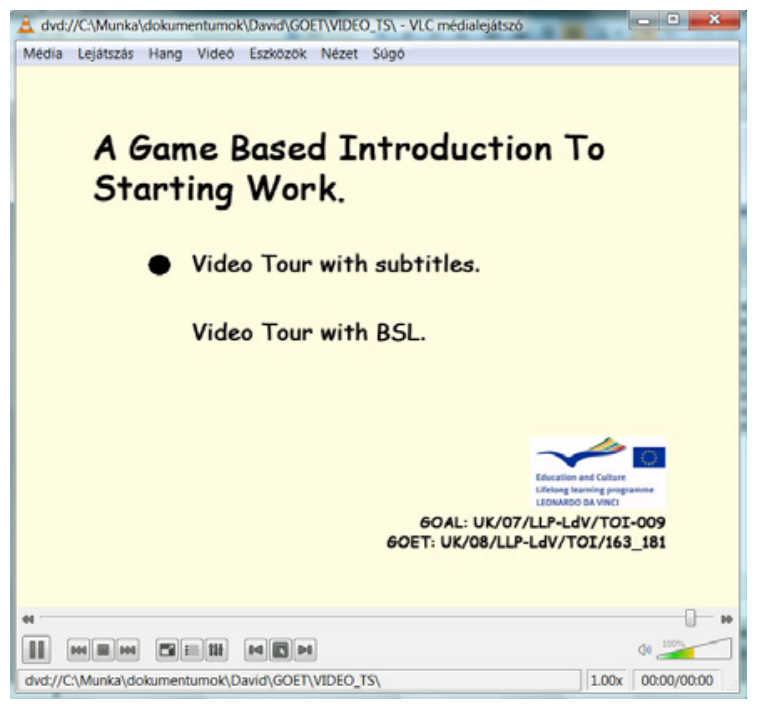

Figure 2: There is an option for hearing impaired users.

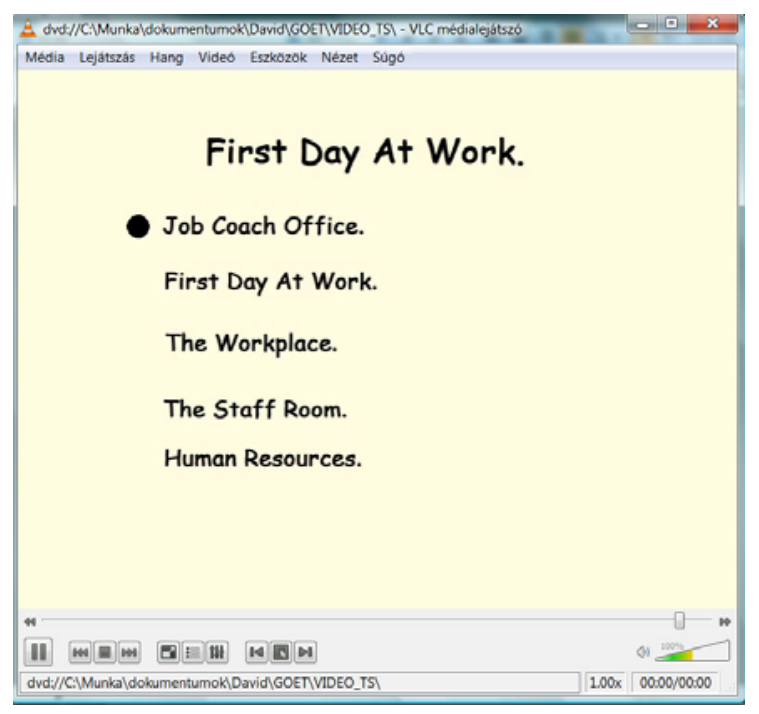

Figure 3: Themes of the 3D Work Tour.

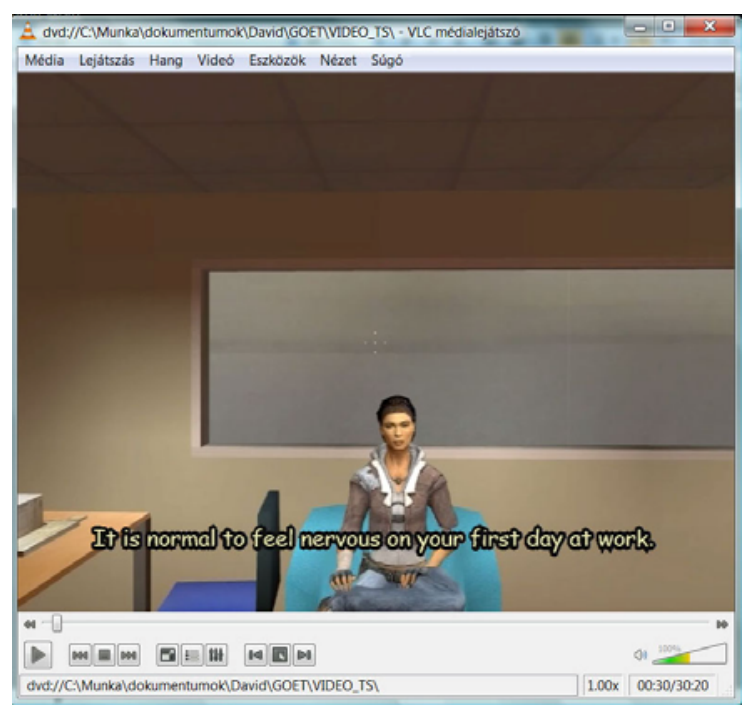

Figure 4: Using subtitles and sound files 


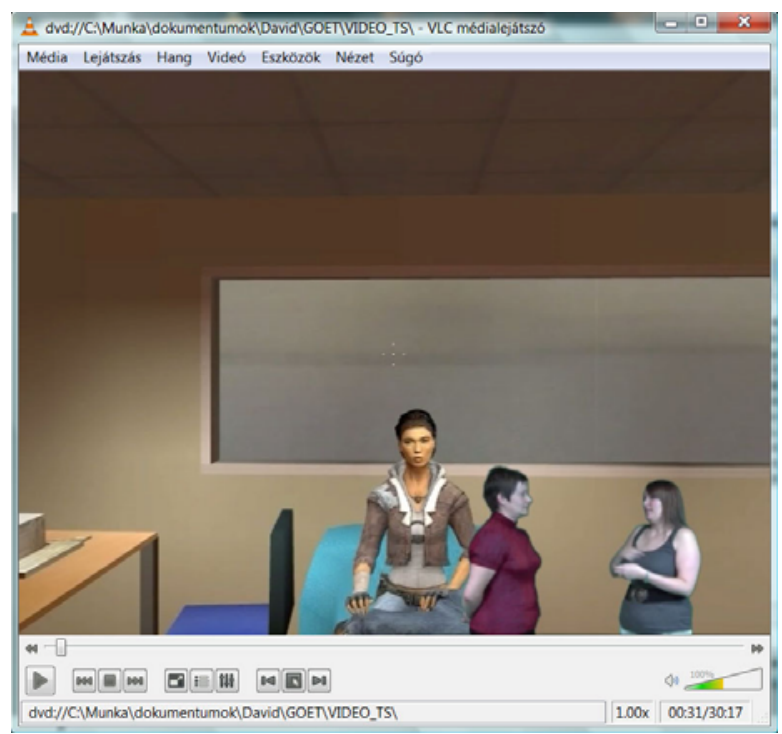

Figure 5: Using BSL.

The user interface is very simple and very clearly organised. It is importation for the target group, because in this way they are able to concentrate on the new information being presented rather than any additional burden created by non-intuitive navigation. The VR environment and avatars are realistic and look similar to the work-based environments and people in the real world.

\subsection{Cheese factory}

Cheese factory: teaches the students using fractions and percentages based on the popular Tetris Game (Fig 6).

The user interface of this game is simple too. The instructions are clear, the colours are appropriate effect, and they are in harmony.

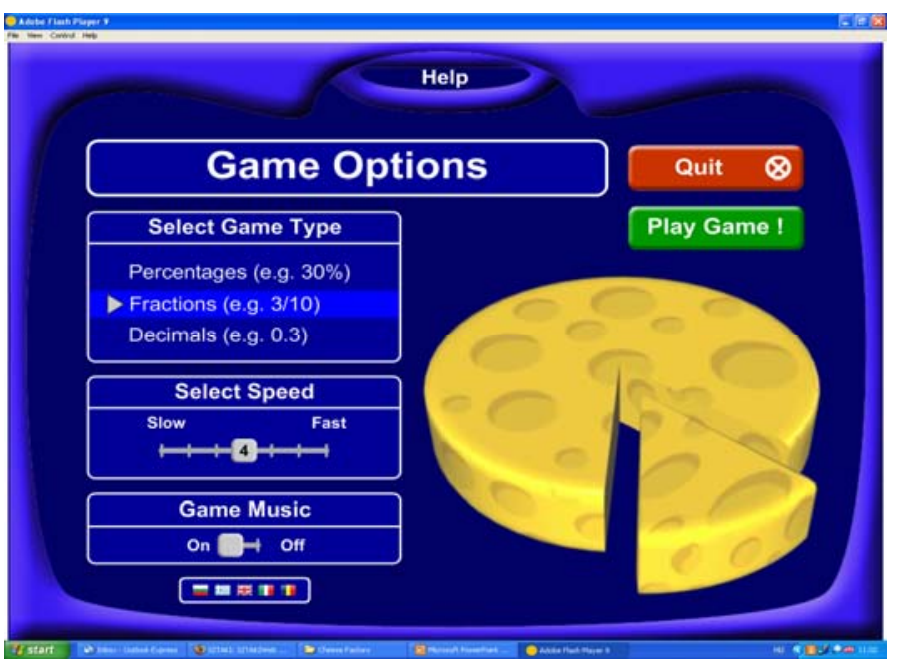

Figure 6: Options in the game.

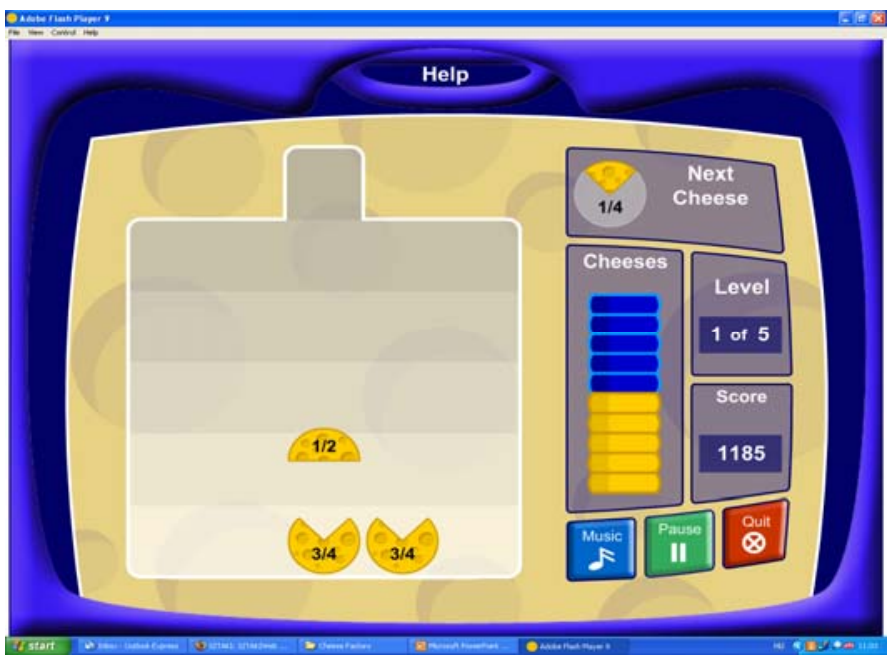

Figure 7: Showing the process of the game.

The buttons are enough big for users with fine motor skills difficulties. The users' results are shown on the right side of the game and the next piece of the cheese is also shown. These features help the user in their ongoing learning tasks (Fig 7).

\subsection{My Appearance}

My Appearance: teaches the students' everyday "morning" tasks from getting up until leaving home using a Flash game. The graphic interface of the game is clear and understandable, and cartoonlike. After selecting the initial settings, for example name, gender and the time to get up, the game starts (Fig 8-9).

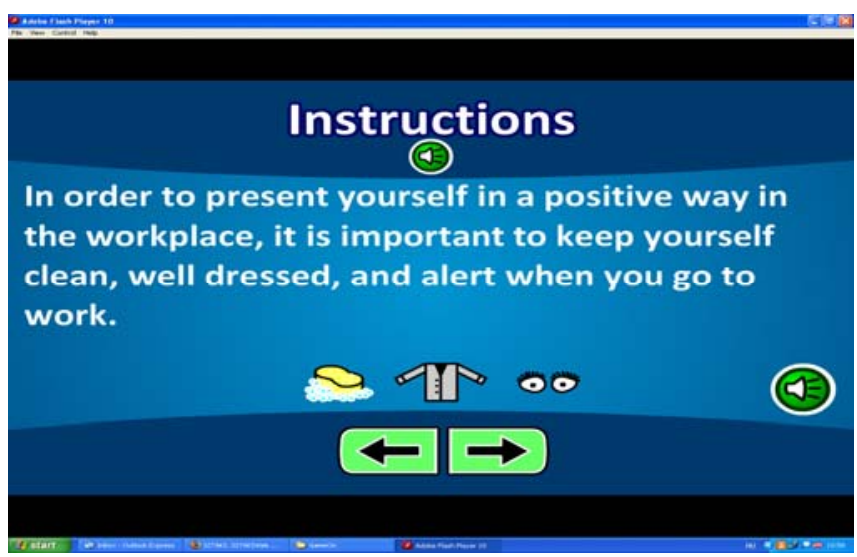

Figure 8: The instruction screen 


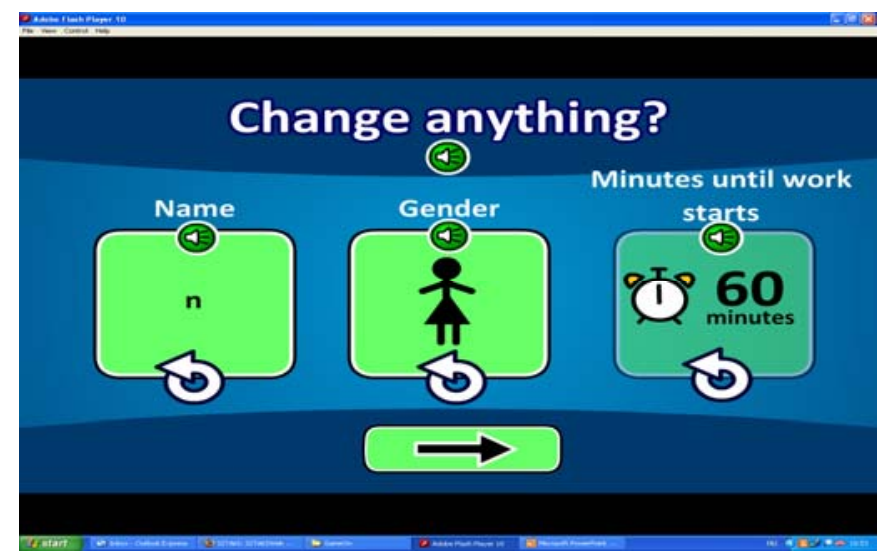

Figure 9: Initial settings.

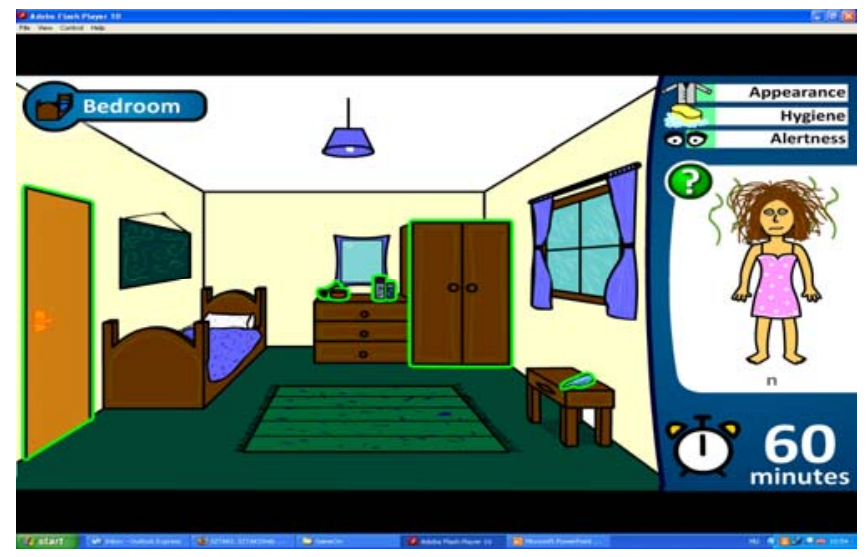

Figure 10: After getting up.

It simulates the sequencing of morning tasks in preparation for leaving for work, and the structure of the game is very consistent. For example after getting up, the user's avatar representation has its hair uncombed and starts with a "smelly" disposition (!) (Fig 10). After having a shower, getting dressed (Fig. 11) and eating breakfast (Fig 12), the user's avatar is ready to leave for work and its appearance improves (Fig 13).

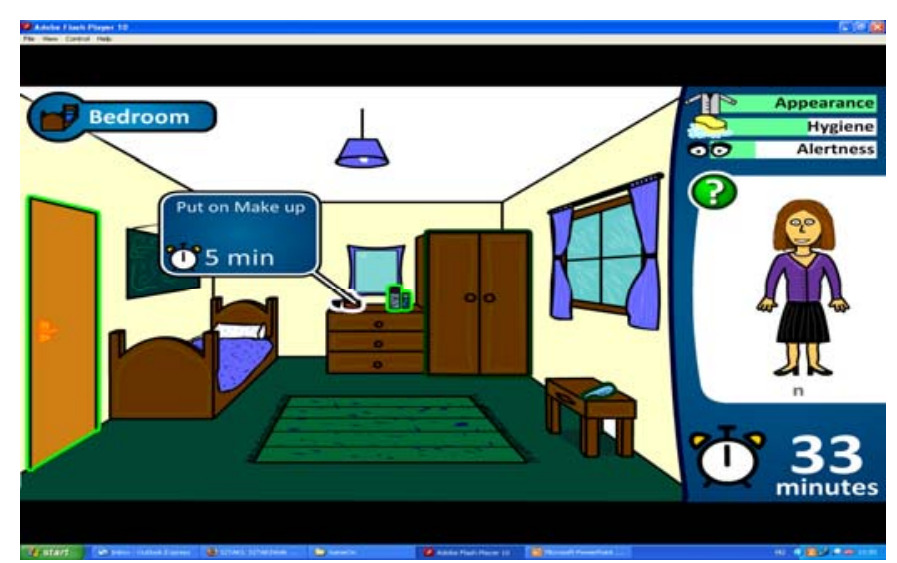

Figure 11: After having a shower and getting dressed.

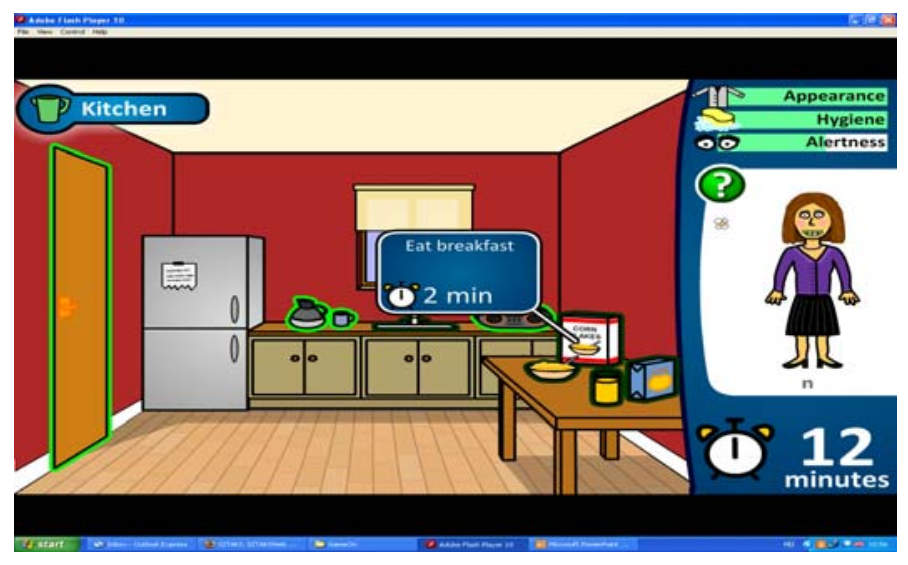

Figure 12: Eating breakfast.

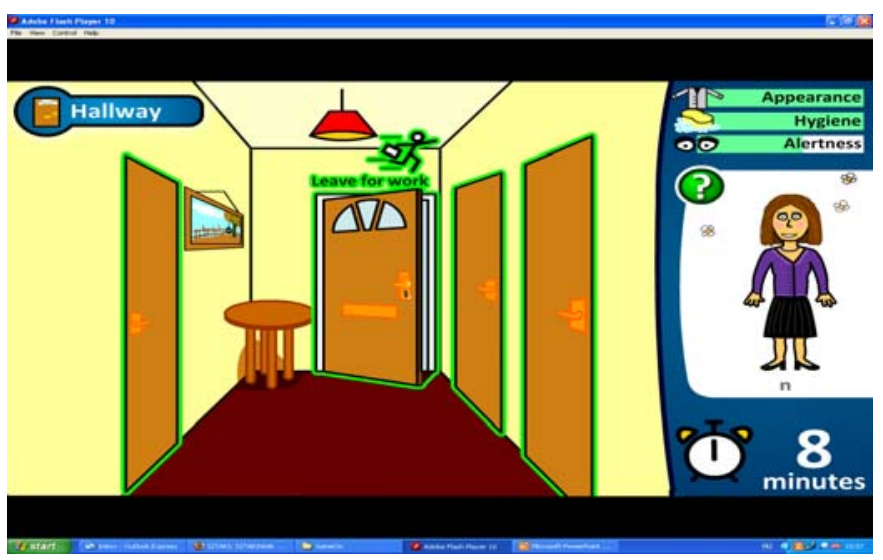

Figure 13: Ready for leaving home

At the end of the game the user receives feedback on his/her performance using sound, subtitles or BSL (Fig 14). If the user forgets to wash his/her hands or forget to have a morning drink, the game doesn't interfere - it lets the user make mistakes and learn from doing so (Fig 15). There is a print option too for further feedback on user performance (Fig 15).

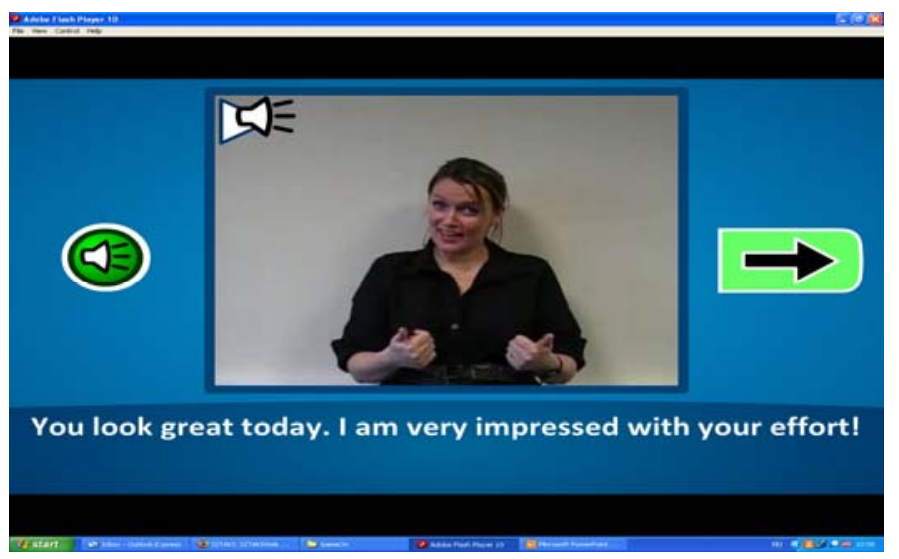

Figure 14: Results feedback in BSL subtitles. 


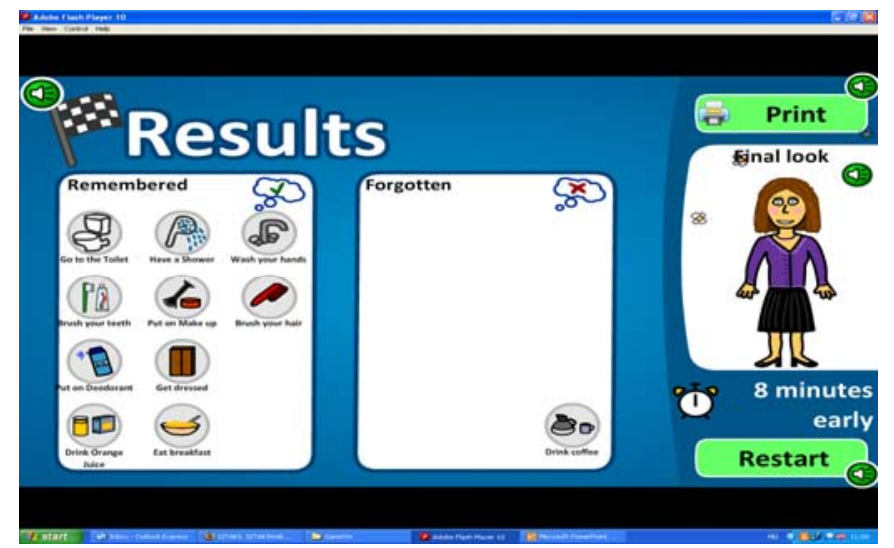

Figure 15: Showing the result graphically.

\subsection{Route Mate}

Route Mate: helps the client to plan and independently carry out their route to work developed on the Android Operating System [12], which is currently used by the HTC Dream \& HTC Hero (available as T-mobile's G1 and G2 phones), the HTC Magic (available from Vodaphone \& Orange), Samsung's 17500 (aka Galaxy) and InstinctQ from (available from O2). Google claim there will be at least 18 models using Android worldwide by the end of 2009 .

Important user-scoped design aspects are:

- The use of familiar symbols to the target audience, specifically designed for the project, along with BSL signing tracks (Fig. 16)

- The use of a rotating map which orientates itself depending on the direction of travel.

- Adding the street entry field to accurately locate position.

- Option to allow user to select a type of reminder, e.g. cross road.

- Provision of a help screen relevant to the type of reminder, e.g. cross road.

- Text in lower-case and Comic Sans MS or Berlin Sans FB for easier reading, and screen reading as alternatives for all text.

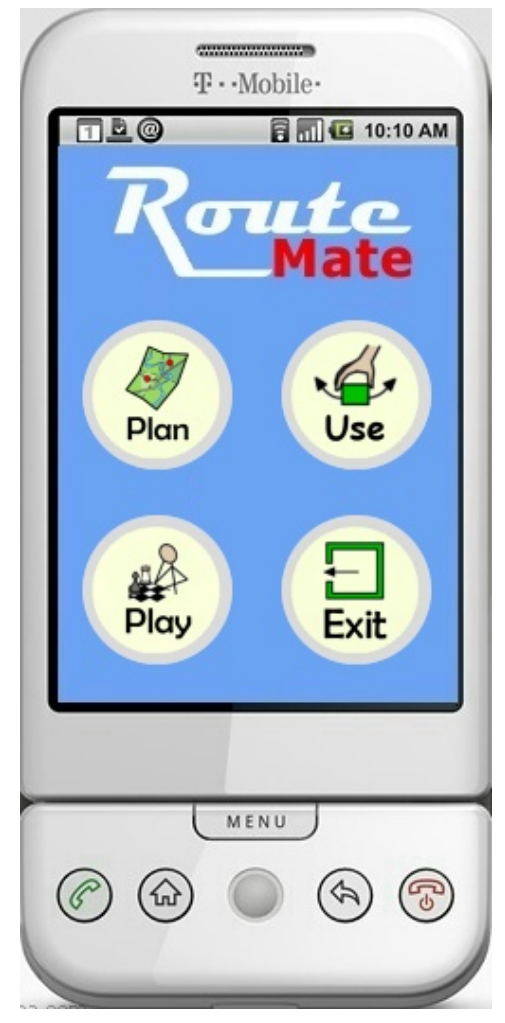

Figure 16: Main menu interface.

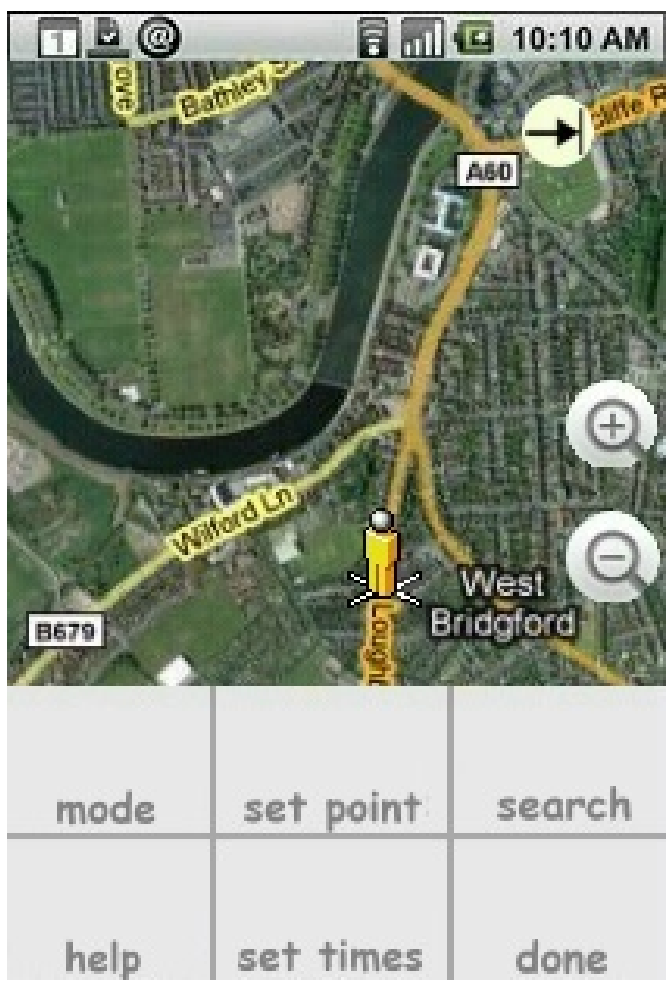

Figure 17: Map views in Plan mode.

When the map screen is first loaded, it will be displayed with the top of the map being north, however when the user moves, the map will rotate itself to the direction of user travel (Fig. 17). Users can also set an alarm for what time they want to 
leave for, or arrive at, work using the 'set times' button and using 'set point' to indicate a point of interest on their current location. Additionally the user can search for a location using the 'search' button. The 'mode' button allows the user to change the view of the map, selecting from satellite view or map view [14].

The route status is also displayed, a preview of the next point title, and an estimated time of arrival ('arrive at'). The route status gives a quick indication of whether they are on time, running late, or are off course. The 'arrive at' field allows the user to decide whether they should speed up to get to work on time (Fig 18) [14].
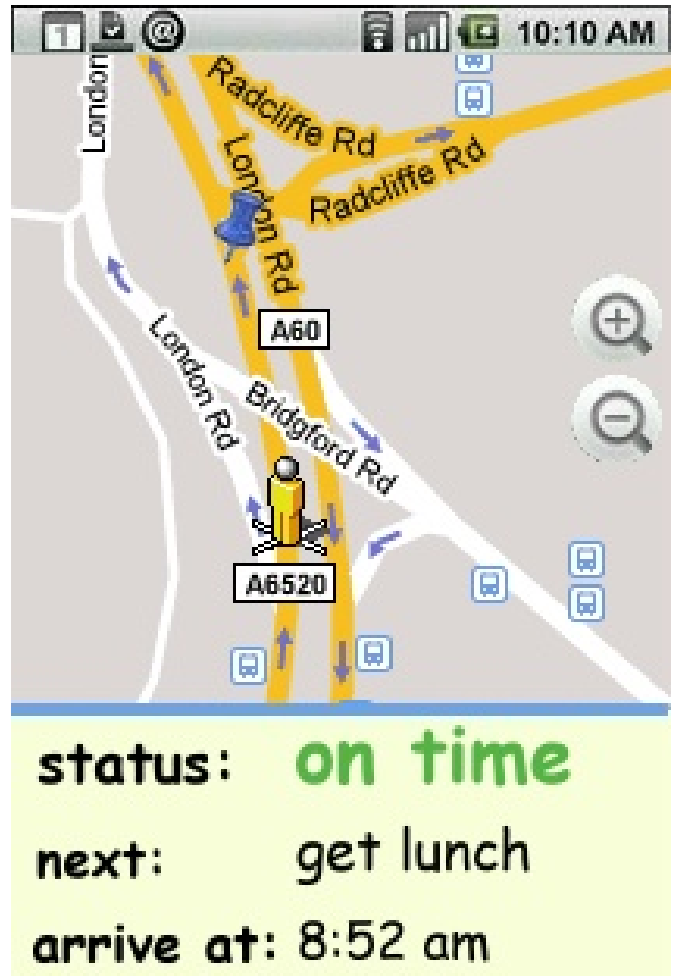

Figure 18: Map view of the Use mode.

If the user diverges from their course a warning message will be displayed, accompanied by the 'status' field indicating 'Off Route' (Fig 19). As well as compensating for poor memory skills, these location-based reminders may aid concentration, confidence and stress management as users' errors are detected early on (e.g., divergence from planned route, possible lateness) [14]

On arriving at a point of interest, the corresponding relevant image (if added) and the point title will be shown (Fig 20). The user can view this item in full screen mode showing a larger picture, title and description by pressing the 'full screen' button. The system will also offer help in road safety producing reminders based on location when roads are encountered to cross, and feedback in terms of actual performance, e.g., advice if arriving late [14].

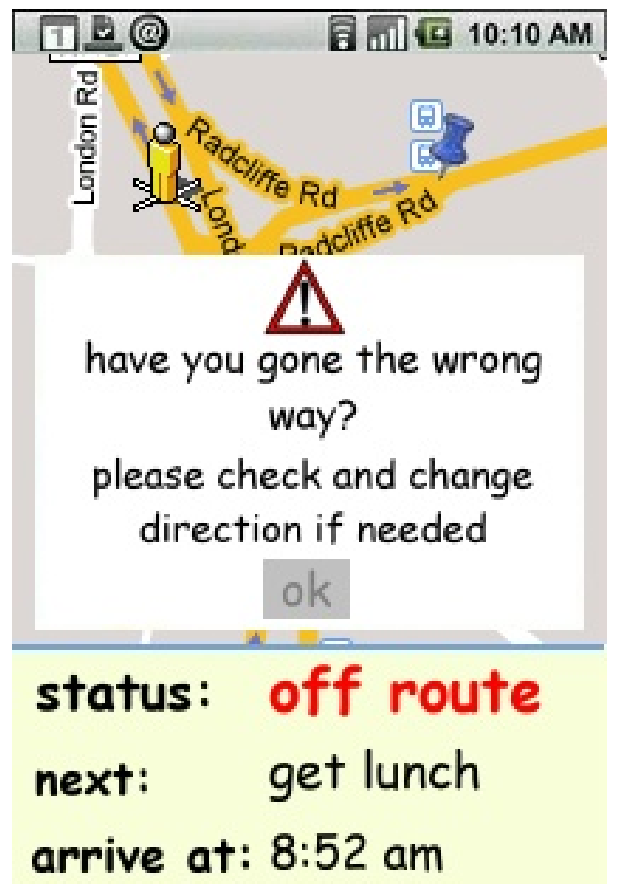

Figure 19: Off-route warnings.

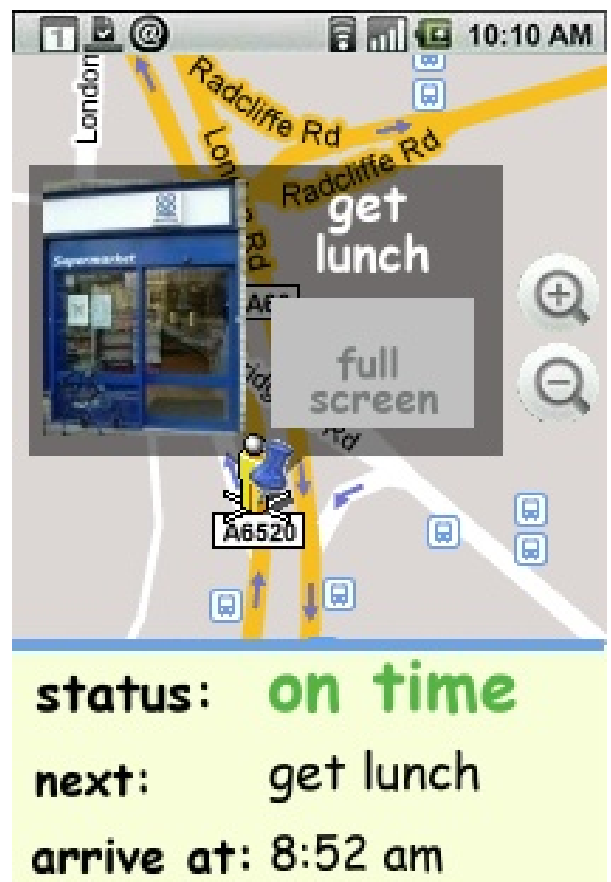

Figure 20: Pop-up window shows the image.

\subsection{VR supermarket}

VR supermarket: helps to teach students about money management skills within a store environment developed using Flash.

The program doesn't require installation. After selecting the difficulty level the game is launched. The player enters the virtual supermarket, and is 
given a virtual wallet, shopping list and shopping cart (Fig 21).

The goods on a given shelf are displayed with their names, prices and images attached to them. To place an item to the shopping cart, the player only has to click on the given item (Fig 22).

To close the window the player has to click on the big red arrow or on the space beside the panel. The shopping cart and the shopping list buttons remain available (Fig 22).

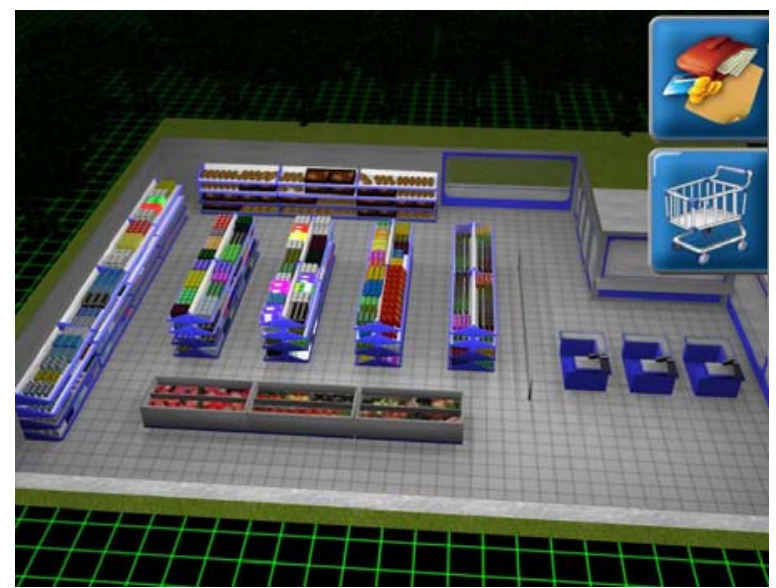

Figure 21: Entering the supermarket.

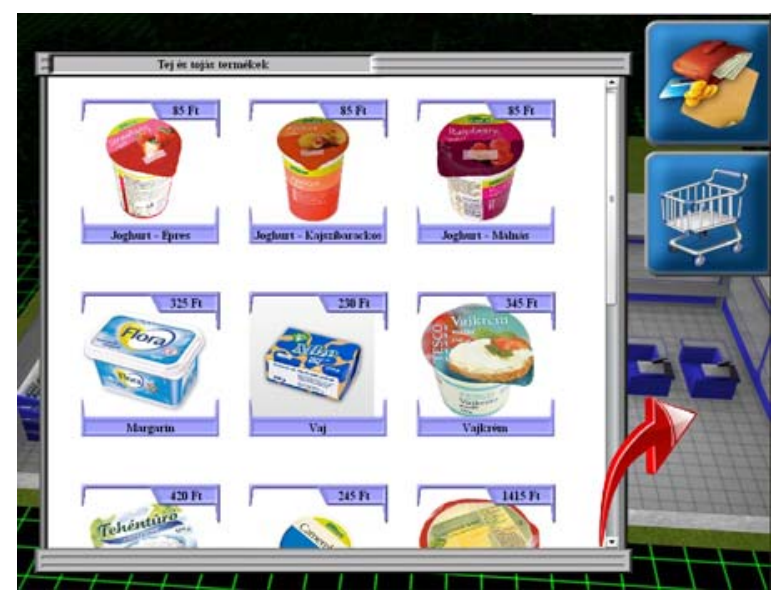

Figure 22: The virtual shelf contents.

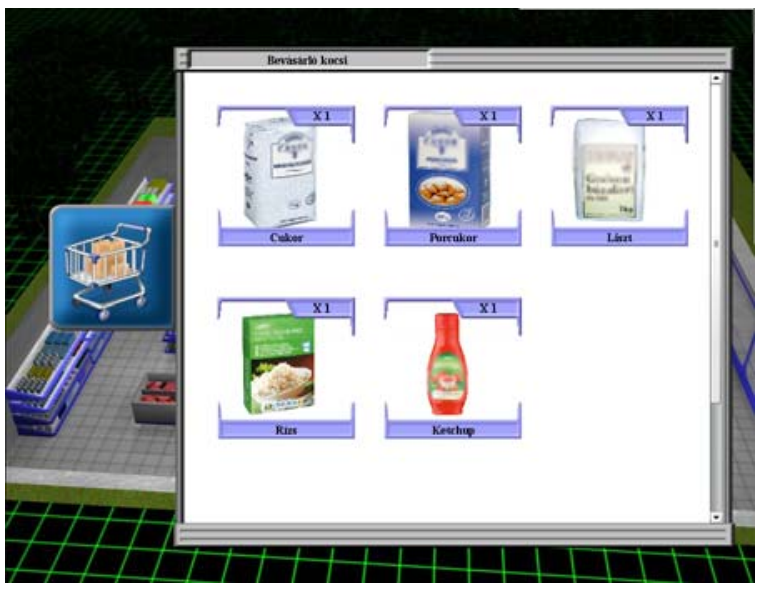

Figure 23: The content of the shopping cart.

In the shopping cart all items are displayed with their image, name and quantity. The player may remove any of the items by clicking on them. To close the window the player has to click on the picture of the shopping cart or on the picture of the store in the background (Fig 23).

Before paying, the bar code scanner registers the price of each item in the shopping cart one by one. During this both the cashier and the cash register will give feedback to the player (Fig 24).

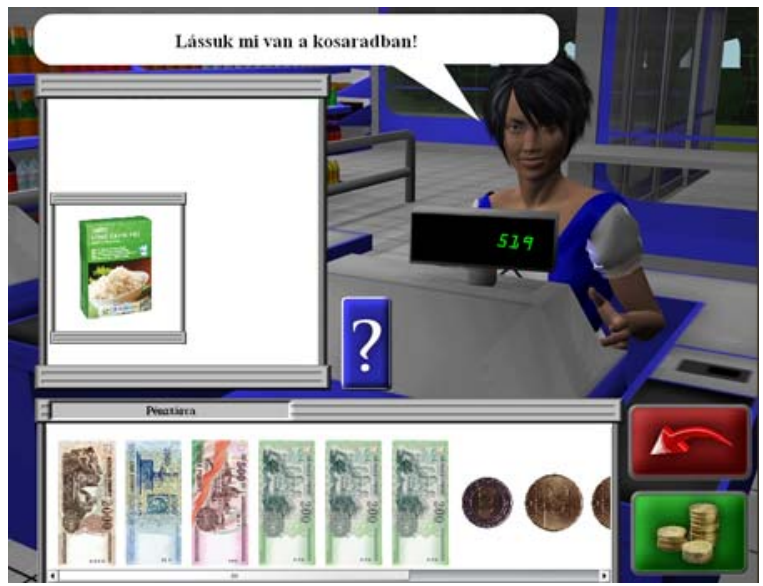

Figure 24: The cashier.

To pay for the items the player has to place a sufficient sum of money onto the drop panel by clicking the separate banknotes and coins in the wallet and then hitting the pay button. After payment the cashier gives change if necessary, and the "go home" button appears to finish the task.

If the player has a insufficient amount of money or has forgotten something, the "back" button leads the user back into the store.

Clicking on the "help" button reveals a small panel on which the paid amount of money is shown. 


\section{USABILITY EVALUATION OF THE USER INTERFACES OF THE GAMES}

A 5 point Likert Scale close-ended questionnaire for testing the user interfaces of the newly developed serious games was developed.

Likert Scales: Likert scales are scales on which the participants register their agreement or disagreement with the statement. "_Strongly Disagree, _ Disagree, _Neither Agree nor Disagree, _ A Agree, _Strongly Agree" is a five-point scale.

This questionnaire contains 29 questions in 4 groups:

- To what degree the games were enjoyed? (6 questions)

- Questions concerning the usability of the software (4 questions)

- Questions concerning the software's manageability: (9 questions)

- Questions concerning the graphics (10 questions)

For example the group "Questions concerning the usability of the software" has the following questions about:

- Does the software display realistic situations?

- Were the situations presented relevant and important to the learning objectives?

- Are you satisfied with the quantity and diversity of the questions used?

- Was the software easy to use?

The final question was an open ended question where the user was able to write his/her own suggestions.

Based on the evaluation results we iteratively developed the user interface of these games. The results are also being used to iterate design principles for the development of serious games for intellectually disabled students derived in previous research projects including $[17,18,19,20]$ :

Ensure presentation at appropriate speed - it is essential that speed of presentation is appropriate for the particular target group, and may be modified during the iterative user-centred design process

Allow users to go back - essential for all users, and especially those who may have organisational, information processing and/or memory difficulties.

Allow User Control - allow for user customisation based on user preference; for example, some users with dyslexia or visual impairment have distinct colour and contrast requirements, others may wish to slow things down, or to use keyboard access.

Text - make any text plain text (rather than images or graphics), follow Clear Text for All guidelines (see WCAG 2.0 [15], W3C [16]), no dense blocks of text, plain native language.

Text Alternatives: Provide text equivalents for non-text content, including auditory and visual components, so that it can be changed into other forms people need, such as Braille, speech, symbols, other languages including sign language.

Colour - never convey information by colour alone.

Contrast - ensure sufficient contrast so that it is easier to distinguish items, both visual and auditory.

Navigable - help users navigate, find content and know where they are: by placing navigation information in the same place (usually at the top) and ensuring that it is consistent and simple, using maps when appropriate, using home and back buttons, providing context and orientation information.

Maintain organisation - instructions, buttons, clearly displayed and in the same place (often at top) throughout presentations.

Links - use unique and informative text descriptions for any hyperlinks (never click here!).

Use accessibility features - HTML/XML have inherent accessibility features (e.g., alt text, long desc) which should always be used; other formats (e.g., Java, Flash, Games environments) are not necessarily accessible, although this is improving with more recent versions having accessibility features, which should be used; provide alternatives where possible.

Design simply - in simple layouts, it is relatively easy to draw attention to important features and differences; in more complex layouts it becomes harder to highlight features, thus making presentations even more complex.

Use fallbacks - provide alternatives, provide equivalent content as accessible HTML when possible and design for graceful transformation (such as reflowing).

Robust - make systems consistent and error free, provide appropriate error messages and error catching. 
Aim for compatibility with assistive technologies - e.g., screenreaders, text-tospeech, zoom features.

Allow keyboard access - ensure the system can be controlled from the keyboard and not just by using the mouse.

Seizures - do not include elements that are known to cause seizures, for example by having elements that flash or have particular spatial frequencies

Using these constantly reviewed design principles we can develop more effective serious games for people with intellectual disability.

\section{CONCLUSION}

In this paper we have discussed the design and evaluation of five serious games' and their user interfaces. These serious games were developed for students with intellectual disability to help them in activities of daily living, and specifically in managing a budget. We have demonstrated the main games' design questions and our solutions for students with intellectual disability. It was very important to design the user interfaces for maximum accessibility and usability. In this way we have minimised the additional cognitive load on the user while navigating within the serious games and corresponding tasks. In order to achieve these goals we have followed published design guidelines, and placed emphasis on using gamelike graphics, animations and auditory output to promote user engagement and to provide alternatives to text.

The detailed pedagogical tests will run until June 2010.

We will demonstrate our games, and their usability testing at the conference.

\section{ACKNOWLEDGEMENT}

This project has been funded with support from the EU's Transfer of Innovation Leonardo da Vinci Lifelong Learning Programme, Game on Extra Time, GOET Grant Agreement number: UK/08/LLP-LdV/TOI/163_181 for. The authors would like to thank Steven Battersby, Nick Shopland and Lajos Harmath for their programming efforts in the development of the se games.

\section{REFERENCES}

[1] Steinkuehler, C. (2006) Massively Multiplayer Online Games - Based Learning, M3 Interdisciplinary Aspects on Digital Media \&
Education, Workshop, Wien, Austria, Nov. 23, 2006., pp. 15-16.

[2] Lowenstein, D (2002) Essential facts about the video and computer game industry, Website found at: http://www.idsa.com/pressroom.html

[3]Serious Game Iniciative

http://www.seriousgames.org/

[4] Serious Games Networking Portal

http://seriousgames.ning.com/

[5]Serious Games Institute

http://www.seriousgamesinstitute.co.uk/

[6]Serious games blog:

http://seriousgamesblog.blogspot.com/

[7] Koops, M.C. (2008) Digital adventure gamebased learning. http://www.drkoops.nl

[8] Prensky, M. (2001) Digital natives, digital immigrants. On the Horizon, NCB University Press,

[9](5)[9]Brown, D.J., Shopland, N., Battersby, S., Tully, A., Richardson, S. (2009) Game On: accessible serious games for offenders and those at risk of offending, Journal of Assistive Technologies, 3(2): 13-25.

[10] Sik Lányi, C. (2008) Multimedia Software Interface Design for Special Needs Users, Encyclopedia of Information Science and Technology, $2^{\text {nd }}$ Edition, IGI Global

[11] Shneiderman, B. (2003). Leonardo's Laptop, Human needs and the new computing technologies, MIT Press, pp. 71.

[12] Department of Health (2001). Valuing People: a new strategy for learning disability for the $21^{\text {st }}$ century. London: HMSO.

[13] LSC, 2006. Accessed on 11th December 2009 from www.Isc.gov.uk/LSCGOVUK/

[14] Brown D.J., McHugh D., Sik Lányi C., Drozdik D.: (2009) Combining location based services with games based learning approaches in assistive technology, Assistive Technology from Adapted Equipment to Inclusive Environments, 10th European Conference for the Advancement of Assistive Technology in Europe, Florence, Italy, August 31- September 2, 2009, pp. 671-676.

[15] Web Content Accessibility Guidelines (WCAG) 2.0: http://www.w3.org/TR/WCAG20/ 
[16] World Wide Web Consortium (W3C): http://www.w3.org/

[17] Brown D.J., Standen P., Evett L., Battersby S., Shopland N.: Designing Serious Games for People with Dual Diagnosis: Learning Disabilities and Sensory Impairments. In Press in Educational Gaming. IGI Global, editors Pavel Zemliansky; Diane Wilcox.

[18] W3C (1999). Web Content Accessibility Guidelines 1.0, W3C Recommendation 5.5.1999. Retrieved July 7, 2007, from www.w3.org/TR/1999/WAI-WEBCONTENT19990505, W3C
[19] W3C (2008). How to Meet WCAG 2.0: A customizable quick reference to Web Content Accessibility Guidelines 2.0 requirements (success criteria) and techniques. Retrieved May 4, 2007, from http://www.w3.org/WAI/WCAG20/quickref/

[20] Horton, S. (2006). Access by Design: A Guide to Universal Usability for Web Designers. New Riders, Berkeley CA. Retrieved January 3, 2009, from http://universalusability.com/index.html 